Session 1461

\title{
Teaching Workplace Communication in Industrial and Electrical Engineering"
}

\author{
Judith Shaul Norback, Lisa D. McNair, Michael J. Laughter, \\ Garlie A. Forehand, Beverly Sutley-Fish \\ School of Industrial and Systems Engineering/ \\ School of Literature, Communication and Culture \\ Georgia Institute of Technology
}

\begin{abstract}
Georgia Tech has National Science Foundation funding to bring workplace communication into a Technical Communication course. Personal interviews have been conducted with industrial and electrical engineers; supervisors; and senior executives. The results of the interviews have been used to tailor Technical Communication to each engineering discipline. These findings will be described along with the course content and preliminary student assessment data.

This article describes curricula that have been developed through collaboration between investigators gathering data from the workplace and academic instructors teaching a traditional Technical Communication Practices course. The goal is to bring real-world documents and guidelines into the classroom to help students become aware and proficient in the communication practices of their disciplines. This accomplishment will in turn help technicallyprepared graduates also be prepared for the communication needs of various jobs, enabling them to get good jobs and move up the career ladder. Examples of workplace materials and curricula based on the Criteria of Communication Excellence will be provided in the presentation along with specific steps for replication. Results will be provided for use by other undergraduate programs teaching Technical Communication courses.
\end{abstract}

\section{Introduction}

Recent research has demonstrated that engineers entering the workplace need to acquire more proficient communication skills in order to excel in their jobs. ${ }^{1}$ Although the Accreditation Board for Engineering and Technology (ABET) has recently passed criteria that include written and

\footnotetext{
${ }^{*}$ This work was supported by the National Science Foundation under Grant DUE-0231305.

Proceedings of the 2004 American Society for Engineering Education Annual Conference \& Exposition Copyright $\left({ }^{\circ}\right.$ 2004, American Society for Engineering Education
} 
oral communication, ${ }^{2}$ there are still gaps in these competency areas. In 1999, the Society of Manufacturing Engineers conducted a survey of managers, training directors, and manufacturing engineers. Two of the results were: 1) the oral and written communication skills that recent engineering graduates have are not as high as those needed on the job; 2) this gap in competency for oral and written skills was among the 10 most critical discrepancies. ${ }^{3}$

To address these deficiencies, Georgia Tech is conducting a pilot study that integrates workplace communication tools into two Technical Communication Practices courses. The skills emphasized are making workplace presentations and producing workplace documents. The courses are restricted to specific majors: one course is populated by 20 Industrial Systems Engineering (ISyE) students and one course is populated by 20 Electrical and Computing Engineering (ECE) students. The goal is to develop a curriculum that can be specific to individual disciplines. This is being accomplished by employing actual documents collected from the workplace as communication models and adapting skills identified through the interviews into evaluation rubrics used for the students and the instructor of the course.

The project includes four kinds of activities. First, curriculum is created that incorporates documents and communication skills identified through interviews with practicing professionals. Second, students practice their workplace communication skills with personal feedback from their instructor and lab staff. Third, students complete assignments requiring the production of workplace documents such as emails and executive summaries. Fourth, for evaluation purposes, students provide before- and after- examples. For instance, students' presentations are videotaped before and after they receive instruction in presenting.

In this paper, seven topics are covered. First an introduction to the project is given, and second, the highlights of relevant publications are summarized. Third, strategies for teaching workplace communication are described and fourth, the goals and orientation of the project are laid out. Fifth, the Communication Lab involved in the curriculum is described. Sixth, the assessment procedures are identified, and finally, future work is covered.

\section{Highlights of Publications Regarding Writing and Presenting in Engineering}

The publication highlights cover three topics. The first focuses on communication skills needed on the engineers' jobs. The second covers the main tenets of communication instruction, including viewing the workplace as a different "discourse community" from academia. The final topic focuses on the importance of bringing engineering communication tasks into the curriculum and creating curriculum relevant to particular disciplines.

Regarding communication skills, publications have indicated that engineers in the workplace are increasingly required to possess solid writing and oral presentation skills. In a 1993 survey of employers, 70 to 80 percent indicated that communication skills are valuable in new engineers. ${ }^{4}$ Other surveys have documented the need and suggested educational emphases. ${ }^{5678}$ Additional studies indicate that a great deal of a practicing engineers' time is spent communicating. For example, engineers in a 1996 study said "they spent a little over half their day communicating" 
(p. 39). ${ }^{9}$ In a 2001 study, the engineers who responded to the survey spent $64 \%$ of their day on writing, oral presentations, and other oral discussions. ${ }^{9}$ So, not only are communication skills needed for practicing engineers; they spend more than half of their workday using the skills.

The second group of studies, relating to communication instruction, have shown that successful undergraduate communication curriculum requires a collaborative effort, including input from: 1) outside technical communication consultants meeting with faculty;, ${ }^{4,10} 2$ ) communication instructors; ${ }^{11}$ ) industrial advisory board members and faculty; ${ }^{12} 4$ ) interviews with engineering faculty; ${ }^{13}$ and 5) a steering committee established by the technical communication department; including "engineering faculty from all departments, the dean of undergraduate studies, mentor representatives from industry, and technical communication faculty" (p. 690). ${ }^{9}$ In one of the studies, engineering alumni were interviewed regarding the helpfulness of their undergraduate communication instruction. ${ }^{9}$

Most communication instruction efforts do not involve direct contact with the workplace. According to linguistic research, the workplace is a different discourse community from academia. Members of a discourse community "have certain expectations from interaction with their community". They "write in ways that are useful to the community and ... familiar" to community members. ${ }^{14}$ The academic discourse community includes interaction based on essays and reports while the engineering workplace discourse community's interaction is based on contracts, status reports, proposals, technical reports, and technical presentations. ${ }^{15}$ One indication of the difference between the two communities is: in more than 100 engineering departments, less than 40 percent of the reports written included at the beginning a clear statement of the purpose, contents, and results, as reports in the workplace do. ${ }^{16}$

The third topic of publications relates to incorporating engineering tasks into the curriculum and keeping the curriculum discipline-specific. Gathering this information from people executing or supervising the engineering tasks enables the development of instruction with "high functional context." 4 Using this process, the context of the workplace is integrated into the engineering communication course. As a result, students are much more capable of applying the workplace communication skills, learned in the classroom, to their job. ${ }^{4}$

Although across-the-curriculum applications have met with much success, it is widely noted that "what constitutes an effective communication differs from discipline to discipline and from profession to profession." "Discipline-relevant content is believed to motivate learners and provide the contextual use of discipline-specific vocabulary. ${ }^{18}$ This project achieves "high functional context"19 by tailoring discipline-specific tools to instruction that is also useful to most students across engineering disciplines.

\section{Strategies for Teaching Workplace Communication}

Now that the introduction and highlights of publications have been covered, the strategies for teaching workplace communication will be covered. As stated above, the pilot classes are designed to introduce students to a variety of professional documents and presentations that they

Proceedings of the 2004 American Society for Engineering Education Annual Conference \& Exposition Copyright (C) 2004, American Society for Engineering Education 
will be required to produce in the workplace and to provide general skills for completing these communication tasks. The documents include various memos, emails, analytical reports, proposals, research reports, and executive summaries. Three oral presentations of varying length and content are included as well.

The first strategy used to teach workplace communication in Technical Communication Practices is a basic in-class discussion of the issues addressed by this kind of discipline-specific curricula. Students are informed about the sources of the workplace information and how this method of teaching prepares them for communicating and excelling in their jobs. In addition, they complete reading assignments including a textbook chapter based on the information gained in the workplace interviews. ${ }^{20}$ The students' feedback is carefully collected, including completion of assessment questionnaires and in-class discussion of how they view the workplace materials.

Second, the Norback Criteria of Excellence in communication based on workplace interviews are integrated into classroom instruction (please see detailed description of the Criteria in section IV). Instructional tools include guides for constructing communication and criteria for evaluating communication. They are used by both students and the instructor for self assessment, peer assessment, and grade calculation. These tools enable faculty, lab staff, and students to give standardized constructive feedback.

Third, actual workplace documents are provided in class and on a website so students can study actual examples of communication in their fields. Each document is accompanied by contextualizing information that explains the situation requiring the communication, and describes the position and experience of the author. Also, the document type and common uses are described.

Fourth, the course is fully supported by the laboratory resources, including the assistance of the staff and the guided use of video technology. Each student presentation is video-recorded and evaluated by lab staff and the instructor. Lab staff members provide one-on-one consultation.

The fifth strategy is the development of a web-based system. This site provides workplace materials edited for anonymity and criteria to evaluate workplace communication.

\section{Goals and Orientation of the NSF Project}

The project has five goals: 1) the building of prototypes of instructional tools, 2) enhancing the communication skills of undergraduates in two engineering disciplines through use of the tools, 3) integrating the instructional tools with the Technical Communication course, 4) gathering and analyzing multiple types of assessment data, and 5) disseminating the project results.

The orientation of the project places emphasis on the kinds of communication materials and tasks encountered by engineers in their professions. "Job communicative analysis" is used to provide empirical workplace documents and evaluation criteria. This systematic process identifies communication needs in specific kinds of jobs by gathering background information about jobs

Proceedings of the 2004 American Society for Engineering Education Annual Conference \& Exposition Copyright (C) 2004, American Society for Engineering Education 
available in a discipline and collecting information in personal standardized interviews with engineers, supervisors and CEOs. ${ }^{20}$ The documents gathered from this process are edited to provide anonymity for companies, their employees, and their property. The results are used to construct three kinds of instructional tools. First, the communication skills are included in the Norback Criteria of Communication Excellence. This document includes 50 criteria in the following categories:

1. Receiving Messages (These criteria help students prepare for communication by gathering and verifying information about their audience.)

2. Audience Awareness (These criteria help students refine their documents and slides by analyzing characteristics of their audience.)

3. Communication as Problem Solving (These criteria help students resolve differences in perception of methods, tasks, and goals.)

4. Constructing Messages (These criteria help students design and organize documents and slides that efficiently deliver important points.)

5. Delivering Messages (These criteria help students effectively deliver their messages and interact smoothly with their audience.)

The second type of instructional tool being developed is evaluation rubrics, based on the Criteria, that provide guidelines for successful communication. Third, examples of actual documents from the workplace are included in the instruction. The instruction is discipline-specific, with content from industrial engineering and electrical engineering.

\section{The Communication Lab}

The Communication Lab is a facility that includes technological aids for communication instruction, service from trained personnel, and opportunities for self-assessment. It is open for day and night hours 38 hours per week. The lab offers several rooms for student activities, including closed rooms that simulate conference rooms, group study carrels, two video labs, and a 20 -student classroom. Students sign in at the front desk each time they visit the lab, and staff members are trained to assist students in both technical and writing issues. Additionally, students gain workplace communication instruction to list on their resumes, and faculty will write a letter of reference that reflects a student's presentation and writing capabilities.

The pilot classes are taught in the wired classroom located in the Communication Lab. The classroom is equipped with traditional amenities such as whiteboards and podiums, and the instructor and students also have the use of wireless access to the Internet along with a projector and screen that enables electronic visual presentation. In addition, a video system in the classroom makes it possible to record all class sessions, including student presentations. Producer ${ }^{\circledR}$ software, a Microsoft product, enables simultaneous recording of both the student presenter and projected visual aids. Two smaller video systems are also located in the Communication Lab, and staff members are available to assist students in recording their own presentations in a smaller setting. 
These technological tools make it possible to methodically assess the oral presentations that students deliver both to a full audience of 20 classmates and also in a private setting as they practice with their teams. The recorded presentations are digitized and used for assessment purposes in a number of ways. First, students are able to individually practice, record, and perfect their presentation styles by using the video labs. Second, faculty, lab staff, and peers offer detailed feedback to each presenter by viewing the recordings of presentations and applying the communication tools. And, finally, the investigators in this project and the Office of Assessment are using these recordings to formally assess the effects of workplace communication instruction upon student oral presentation skills.

\section{Assessment}

Multiple types of assessment information are being collected in the project. Working with the Office of Assessment at Georgia Tech, the investigators are measuring student progress in two areas, oral presentation and writing. Two instruments that measure pre- and post-instruction skill levels are administered to students.

To assess student improvement in oral presentation skills, each student records a five-minute presentation with slides in the Communication Lab at the beginning and end of the semester. The oral presentation assignment is designed to measure presenters' abilities regarding clear and supported content; logical organization; professional style; and effective visual aids design.

To assess student improvement in technical writing, each student completes a written exercise at the beginning and end of the semester. The exercise is designed to measure writers' abilities in audience analysis; clear and persuasive argumentation; organization, style, and clarity; and document design.

Attitudinal surveys are also distributed. These instruments are designed to measure change in the levels of students' confidence in their communication skills.

\section{Future Work}

In the future, content and delivery of curricula will be modified in response to results from the assessments. Student feedback from questionnaires and surveys will be applied to facilitate understanding and application of materials. Faculty input will also be implemented to construct a method of instruction that is effective both in a discipline-specific mode and in teaching general communication skills across the curriculum. In this way, the curriculum that is developed will be applicable in many schools and universities at different academic levels and for different disciplines, and it will provide an effective tool for teaching communication skills that will be required in the workplace.

Workplace materials will also be used to create evaluation rubrics for more types of documents, including extended reports, written instructions, and graphics. Input from the workplace on other types of commonly used documents will be implemented. The scope of this project will be

Proceedings of the 2004 American Society for Engineering Education Annual Conference \& Exposition Copyright (C) 2004, American Society for Engineering Education 
extended to other disciplines, including Biomedical Engineering, Mechanical Engineering, and Computer Science.

Finally, workplace information will inform classroom materials on how to work successfully in teams. Collaboration is becoming more common in businesses of all kinds, and the ABET criteria focus on team skills as well as communication skills

\section{Bibliography}

\footnotetext{
${ }^{1}$ Sageev, Pneena and Carol J. Romanowski. “A Message from Recent Engineering Graduates in the Workplace: Results of a Survey on Technical Communication Skills," Journal of Engineering Education, v90 n4 (October 2001): 685-693.

2 “2000-2001 Criteria for Accrediting Engineering Programs," Accreditation Board of Engineering and Technology, Baltimore, 2000.

${ }^{3}$ Rogers, Dick, Jr.; M.J. Stratton; and R.E. King. "Manufacturing Education Plan: 1999 Critical Competency Gaps-Industry Updates Competency Gaps Among Newly Hired Engineering Graduates," Society of Manufacturing Engineers, 1999.

${ }^{4}$ Walker, Mirabelle. "Enhancing Students' Learning While Developing Their Communication Skills." Engineering Science and Education Journal, v8 n5 (1999): 201-205.

${ }^{5}$ Pinelli, T.E.; R.O. Barclay; and J. M. Kennedy. "Workplace Communication Skills and Value of Communications and Information UseSkills Instruction-Engineering Students' Perspectives." Proceedings of the IEEE Int'l Communication Conference, 1995: 161-165.

${ }^{6}$ Schillaci, William C. "Training Engineers to Write: Old Assumptions and New Directions," Journal of Technical Writing and Communication, v26 n3 (1996): 325-333

${ }^{7}$ Rogers, Dick, Jr.; M.J. Stratton; and R.E. King. "Manufacturing Education Plan: 1999 Critical Competency Gaps-Industry Updates Competency Gaps Among Newly Hired Engineering Graduates." Technical Report for the Society of Manufacturing Engineers, 1999.

${ }^{8}$ Sageev, Pneena and Carol J. Romanowski. “A Message from Recent Engineering Graduates n the Workplace: Results of a Survey on Technical Communication Skills.” Journal of Engineering Education, v90 n4 (October 2001): 685-693.

${ }^{9}$ Vest, David; Marilee Long; and Thad Anderson. "Electrical Engineers' Perceptions of Communication Training and Their Recommendations for Curricular Change: Results of a National Survey." IEEE Transactions on Professional Communication, v39 n1 (March 1996): 38-42.

${ }^{10}$ Baren, Robert M. and James Watson. "Developing Communication Skills in Engineering Classes." Proceedings of the 1993 IEEE International Professional Communication Conference, October 1993: 432-437.

${ }^{11}$ Quigley, Brooke L. "Designing and Grading Oral Communication Assignments." New Directions for Teaching and Learning n74 (Summer 1998): 41-49.

${ }^{12}$ Mahan, John E., et. al. "Bringing an Emphasis on Technical Writing to a Freshman Course in Electrical Engineering." IEEE Transactions on Education, v43 n1 (2000): 36-42.

${ }^{13}$ Kryder, LeeAnne G. "Mentors, models and clients: using the professional engineering community to identify and teach engineering genres." IEEE Transactions on Professional Communication, v42 n1 (March 1999): 3-11.

${ }^{14}$ Booth, Wayne C.; Gregory G. Colomb; and Joseph M. Williams. The Craft of Research, University of Chicago Press, Chicago, 1995.

${ }^{15}$ Norback, Judith Shaul; Donna C. Llewellyn; Jill R. Hardin. "Integrating Workplace Communication into Undergraduate Engineering Curricula.” OR/MS Today, v28 n4 (August 2001): 33-35.

${ }^{16}$ Blake, Gary. "Watching What You Write.” IIE Solutions, v30 n1 (January 1998): 38-39.
} 
${ }^{17}$ Artemeva, Natasha; Susan Logie; and Jennie St-Martin. "From Page to Stage: How Theories of Genre and Situated Learning Help Introduce Engineering Students to Discipline-Specific Communication." Technical Communication Quarterly, v8 n3 (Summer 1999): 301-16.

${ }^{18}$ Parkinson, Jean. "Acquiring Scientific Literacy through Content and Genre: A Theme-based Language Course for Science Students." English for Specfic Purposes, v19 n4 (2000): 369-87.

${ }^{19}$ Mikulecky, L. and P. Lloyd. "The Impact of Workplace Literacy Programs: A New Model for Evaluating the Impact of Workplace Literacy Programs.” NCAL Technical Report TR93-2, National Center on Adult Literacy, University of Pennsylvania, Philadelphia, 1993.

${ }^{20}$ Norback, Judith Shaul, Joel S. Sokol, Peter J. McGuire, Garlie A. Forehand. "Engineering Workplace

Communication: Presenting and Writing." In Introduction to Engineering through Case Studies, editors Chetan

Sankar and P.K. Raju. Taveneer Publishing Company, Anderson, SC, 2004.

Norback, Judith Shaul; G.A. Forehand; Stephanie A. Jernigan; Alexander B. Quinn. "Teaching Workplace

Communication in Senior Design." Proceedings of the 2002 American Society for Engineering Education

Conference, June, 2002.

Norback, Judith Shaul. "Literary Skills Analysis for Job Training." NCAL Technical Report TR98-07, National Center on Adult Literacy, University of Pennsylvania, Philadelphia, 1998.

Norback, Judith Shaul and Garlie A. Forehand. "Print Use Profiles." Occupations and the Printed Word, ed. P. Barton, ETS Policy Information Center, Princeton, NJ, 1997.

Norback, Judith Shaul. "Skill Levels and Equivalencies: Related Projects and Issues." Strategy Paper for the National Skill Standards Board, Institute for Educational Leadership, Inc., Washington, DC, 1996.

Norback, Judith Shaul and Garlie A. Forehand. "Job Literacy: A Framework for Categorizing Skills and Assessing

Complexity." Technical Paper for the Center for Skills Enhancement, Inc., Princeton, NJ, 1995.

Norback, Judith Shaul. "The Norback Job Literacy Structure.” Technical Paper for the Center for Skills

Enhancement, Inc., Princeton, NJ, 1995.

\section{Biographical Information}

JUDITH SHAUL NORBACK

Dr. Norback is the Director of Workplace and Academic Communication in Industrial and Systems Engineering and a faculty member at Georgia Tech. Her research focuses on workplace communication skills needed by practicing engineers. She has led the workplace communication research and coordinated the activities in the lab and coauthored the communication instruction for undergraduate engineers.

\section{LISA DUPREE MCNAIR}

Dr. McNair is the Coordinator of Technical Communications in the School of Literature, Communications, and Culture and a faculty member at Georgia Tech. She teaches communications courses and has done research and curriculum development for SRA/McGraw Hill and for a number of universities. She has assisted in the workplace communication research and has co-authored the communication instruction for engineering undergraduates.

MICHAEL J. LAUGHTER

Mr. Laughter is an instructor of Technical Communications in the School of Literature, Communications, and Culture at Georgia Tech. He holds a Masters degree in Technical and Expository Writing from the University of Arkansas, and has taught Professional Communications at Tulane. As an instructor in the NSF study, he has coauthored the communication instruction for engineering undergraduates and taught the Practices.

GARLIE A. FOREHAND

Proceedings of the 2004 American Society for Engineering Education Annual Conference \& Exposition Copyright (C) 2004, American Society for Engineering Education 
Dr. Forehand was Director of Research Program Planning and Development at Education Testing Service until February 2000. Garlie teaches and consults in the areas of research design and workplace communication. His research emphasizes curriculum innovation and evaluation. As a consultant to Georgia Tech, he has assisted in the workplace communication research and co-authored the communication instruction for engineering undergraduates.

\section{BEVERLY SUTLEY-FISH}

Dr. Sutley-Fish has experience in curriculum development and training in both academic and workplace settings. Beverly teaches and consults in the areas of organizational behavior, qualitative research and interpersonal communication. As a consultant to Georgia Tech, Beverly has assisted in the workplace communication research. 